\title{
El proceso de captación en la organización terrorista ETA
}

\section{The recruitment process in the terrorist organization ETA}

\section{O processo de recrutamento na organização terrorista ETA}

\author{
Cristóbal Forján Anillo* \\ https://orcid.org/0000-0001-7610-9553 Investigador UNED, Beriain, España
}

- Fecha de recepción: 2021-01-22

- Fecha concepto de evaluación: 2021-04-02

- Fecha de aprobación: 2021-04-30 https://doi.org/10.22335/rlct.v13i2.1395
Para citar este artículo / To reference this article / Para citar este artigo: Forján, C. (2021). El proceso de captación en la organización terrorista ETA. Revista Logos Ciencia \& Tecnología, 13(2), 134-147. https://doi.org/10.22335/rlct.v13i2.1395

\section{RESUMEN}

El reclutamiento de activistas en bandas armadas, de manera general, se explica entre otras cosas por su relación con dos procesos psicosociales básicos, uno de radicalización y otro de polarización social, encaminados a disponer de militancia suficiente. Este artículo analiza desde una perspectiva empírica la captación de militantes de la organización terrorista ETA (Euskadi ta Askatasuna) en España, durante sus años de existencia, con base en la experiencia, investigación y contacto continuo con el mundo nacionalista radical, a partir del estudio de sumarios judiciales de atentados y desarticulaciones de comandos, y de diversos aportes de fuentes internas derivadas de entrevistas, así como de las posturas de expertos en el objeto de estudio, agrupando actitudes comunes no exclusivas y exponiendo limitaciones originadas especialmente en las charlas y entrevistas realizadas a vecinos y víctimas del grupo terrorista, que permiten concluir que ningún planteamiento generalista suple el desarrollo de investigaciones específicas, capaces de esclarecer las particulares causas de cada caso concreto. La mayoría de los expertos coincide en señalar la carencia de un conocimiento práctico exhaustivo del proceso de reclutamiento de terroristas y su comportamiento.

Palabras clave: terrorismo, violencia, reclutamiento, perfiles de autor, nacionalismo vasco, organizaciones terroristas, ETA 


\begin{abstract}
The recruitment of activists in armed gangs, in general, is explained, among others things, by its relationship with two basic psychosocial processes, one of radicalization and the other of social polarization, aimed at having sufficient militancy. This article analyzes from an empirical perspective the recruitment of militants of the terrorist organization ETA (Euskadi ta Askatasuna) in the Spanish State, during its years of existence, based on experience, research and continuous contact with the radical nationalist world, and in the study of judicial summaries of attacks and dismantling of commandos, various contributions from internal sources derived from interviews, as well as the positions of experts in the object of study, grouping common non-exclusive attitudes and presenting limitations originated especially in the talks and interviews carried out with neighbors and victims of the terrorist group, which allow to conclude that no generalist approach substitutes the development of specific investigations, capable of clarifying the particular causes of each specific case. Most experts agree that there exists a lack of comprehensive working knowledge of the terrorist recruitment process and its behavior.
\end{abstract}

Keywords: Terrorism, violence, recruitment, terrorist profiles, basque nationalism, terrorist organizations, ETA

\title{
RESUMO
}

O recrutamento de militantes em gangues armadas, no geral, explica-se, entre outras coisas, por sua relação com dois processos psicossociais básicos, um de radicalização e outro de polarização social, visando uma militância suficiente. Este artigo analisa desde uma perspectiva empírica o recrutamento de militantes da organização terrorista ETA (Euskadi ta Askatasuna) na Espanha, durante seus anos de existência, com base na experiência, pesquisa e contato contínuo com o mundo nacionalista radical, partindo do estudo de resumos judiciários de atentados e desmantelamento de comandos, e de contribuições diversas de fontes internas derivadas de entrevistas, bem como as posições de especialistas no objeto de estudo, agrupando atitudes não exclusivas comuns e expondo limitações originadas especialmente nas palestras e entrevistas realizadas aos vizinhos e às vítimas do grupo terrorista, o que permite concluir que nenhuma abordagem generalista substitui o desenvolvimento de pesquisas específicas, capazes de esclarecer as causas particulares de cada caso concreto. A maioria dos especialistas concorda que falta um conhecimento prático abrangente do processo de recrutamento de terroristas e seu comportamento.

Palavras-chave: terrorismo, violência, recrutamento, perfis de autor, nacionalismo basco, organizações terroristas, ETA

El apoyo social a la organización terrorista ETA, a lo largo de su dilatada historia de 60 años, fue evolucionando desde la épica revolucionaria de los que luchaban por la libertad de Euskal Herria y contra el franquismo, pasando por la época post franquista y de transición en la que se mantuvo ese poso de lucha contra el régimen y aspiraciones de la independencia que se tradujo en los años más duros y sangrientos (años de plomo), hasta la manifestación de la reacción social más adversa y espontánea tras el asesinato del joven concejal de Ermua, Miguel Ángel Blanco (espíritu de Ermua), que finalizó en los años 1990 y 2000 con un claro rechazo social, producto del hartazgo de la sociedad vasca y española tras más de 800 víctimas y de miles de heridos y exiliados (Domínguez, 2004).
Pero más allá de la evolución de ese apoyo social, que lógicamente también encauzó el final de una banda terrorista desdibujada a todos los niveles (internacional, social, etc.), de acuerdo con López (2014), la subsistencia de la última organización terrorista de Europa invita al lector a hacerse varias preguntas: ¿quién militaba en ETA?, respuesta que lógicamente debe ser abordada desde varias perspectivas (social, psicológica, etc.), ¿y cómo se llevaba a cabo esa captación para la organización?, interrogante que se abordará en el presente artículo.

A lo largo de esa extensa historia de la organización, tanto la financiación económica como la captación de nuevos miembros serán, junto al apoyo social referido 
anteriormente, dos de los pilares fundamentales para la propia actividad de la banda criminal. Hoy en día, no se ha podido hacer un balance exacto de qué presupuesto necesitaba la organización para su propia subsistencia y el sostenimiento de todas sus estructuras y comandos armados, pero es evidente que sufragaba su acción principalmente a través del denominado impuesto revolucionario, los secuestros, las herriko tabernas (bares del pueblo), la compra de bonos de organizaciones ilegalizadas como SEGI ('seguir'), la contribución voluntaria (huchas de Gestoras Pro-amnistía), etc.

El esfuerzo perenne por parte de la organización terrorista a fin de disponer de una numerosa infraestructura personal, así como de viviendas y pisos de seguridad, provocó que gran parte de su actividad consistiera en la captación de nuevos miembros, tejiendo toda una red de laguntzailes o colaboradores dependientes en la mayoría de los casos de un comando de liberados, creando verdaderos conglomerados o complejos de comandos, como por ejemplo, el Complejo Donosti.

El propio estudio y análisis sobre el modus operandi de los comandos desarticulados por las Fuerzas y Cuerpos de Seguridad ha permitido un conocimiento más amplio sobre cómo se producía la incorporación de nuevos activistas, siendo evidente que el movimiento juvenil y las propias organizaciones radicales, incardinadas en el autodenominado Movimiento Liberación Nacional Vasco (MLNV), así como los partidos políticos y los sindicatos constituían el principal nicho de captación para la banda.

Una sinopsis y análisis sobre la historia de ese movimiento juvenil radical permitirá entender, en buena lógica, por qué la cantera principal de reclutamiento de los nuevos activistas para la banda criminal ETA se encontraba entre los jóvenes. Una banda armada surgida entre un grupo de estudiantes radicales, escindidos del colectivo EKIN, dio lugar a todo un conglomerado de organizaciones agrupadas bajo las siglas del MLNV, que la propia organización terrorista controlaría a través del tiempo, inicialmente a través de KAS (Koordinadora Abertzale Sozialista: 'Coordinadora Patriota Socialista') y posteriormente de EKIN, organización distinta de la anterior, constituida en 1959 y considerada el comisario político de ETA, reservándose así la vanguardia y control del movimiento.

En ese contexto de expansión del MLNV, articulado en torno a los frentes militar, político, obrero y de masas, en el año 1978 se constituyeron las Juventudes de KAS, de las cuales surgiría posteriormente la mítica organización juvenil JARRAI ('continuar'), que iría adoptando diferentes franquicias, como HAIKA ('levantarse') y SEGI, hasta llegar a la actual, ERNAI ('atento'), eludiendo la acción judicial.

Desde su nacimiento en 1978, el frente juvenil va prácticamente de la mano y complementando la lucha de la organización terrorista ETA, por lo que, en lógica, la captación tiene lugar en el seno de ese movimiento, conformado por jóvenes comprometidos y aguerridos, adoctrinados y cohesionados a través de la propia praxis y ortodoxia fijada en macro eventos propios (Gazte Topagunea: encuentro de jóvenes, congresos juveniles, campamentos, etc.).

En la primavera de 1988, y en el contexto de esa ramificación o expansión del MLNV nace el sindicato estudiantil Ikasle Abertzaleak (estudiantes patriotas), con fuerte presencia a lo largo de su historia en el seno del movimiento universitario, y con el objetivo de crear una Escuela Nacional Vasca. De sus filas surgirían también activistas integrados posteriormente en los comandos de la banda.

El 29 de marzo de 1992 era descabezada la dirección de la organización terrorista, tras la detención en Bidart (Francia), de Francisco Múgica Garmendia 'Artapalo', José Luis Álvarez Santacristina 'Txelis' y José María Arregui Erostarbe 'Fiti', a raíz de lo cual se llegó al conocimiento de la existencia de unos grupos $\mathrm{X}$ e $\mathrm{Y}$, encargados de llevar a cabo sabotajes contra los objetivos tradicionales de ETA, como estrategia diseñada por Txelis (máximo dirigente del aparato político de ETA, detenido en la fecha citada junto a los también jefes del aparato ejecutivo y logístico de la banda armada) con funcionamiento desde el año 1989, y que posteriormente pasaría a denominarse kale borroka (violencia callejera).

Las funciones de esas estructuras juveniles fueron, más allá de sus propios fines, las de complementar la actividad de la organización terrorista ETA. Los actos violentos produjeron a lo largo de los años cuantiosos daños materiales y económicos, a la vez que ejercían una gran presión sobre las propias víctimas de las acciones, quienes en numerosas ocasiones sufrían esos ataques en sus propios domicilios, negocios, etc. Esta era una lucha caIlejera que la banda armada aprovechaba para suplir su presencia durante las treguas de alto al fuego.

Quedó acreditada y probada esa actividad en la sentencia 50/2007 del Tribunal Supremo, con fecha 19/01/2007, que declaraba a JARRAI/HAIKA/SEGI asociaciones ilícitas, ratificando así la sentencia 27/2005 de la Sección IV 
de la Sala de lo Penal de la Audiencia Nacional (AN), al dictaminar que dichas organizaciones complementaban la estrategia de ETA.

En ese contexto histórico de amplia base social, bajo el enmascaramiento de la verdadera finalidad de dichas organizaciones y la instrumentalización de las reivindicaciones (creación de una Escuela Nacional Vasca, etc.), el movimiento juvenil radical en su conjunto fue el banderín de enganche de la juventud; de ahí que tras militar en Ikasle Abertzaleak, JARRAI, HAIKA o SEGI, en partidos políticos afines (Batasuna) e inclusive en sindicatos nacionalistas (LAB), en lógica evolución con el compromiso adquirido se produjera el salto posterior a la organización terrorista ETA.

\section{Inicios del proceso de captación}

El término perfil siempre ha sido utilizado para describir una parte de algo, visto lateralmente y no percibido en su totalidad, salvo sus elementos más definitorios. Cuando hablamos de captación como percepción por los sentidos de lo que sucede alrededor, resulta necesario definir este vocablo en la materia que se trate, en este caso perfil terrorista, a fin de conocer, con exactitud, la integración de miembros en la banda armada y la senda que han seguido.

Garrido y Gómez (1998, p. 264) definen la entrada "Perfil del criminal" como: "El rastreo de patrones de conducta que vienen a representar un cierto estilo de vida", pero, profundizando conceptualmente en este contenido, debe entenderse como perfil terrorista al conjunto de aquellas características personales que poseen los militantes de una organización y también a las adquiridas además durante un proceso de socialización, conducente a su inserción en las filas de una banda terrorista.

Este proceso involucra pasos cronológicos en determinados periodos de la historia de ETA, siguiendo su aprendizaje modélico de otras conductas de militancia y recogiendo una experiencia de perfeccionamiento durante las acciones violentas que se ejecutaron, en conjunto indiciarias policialmente de formas de actuación de comandos, evidentes en los atentados perpetrados, siendo preciso un análisis completo del modelo de captación o integración en la organización para una investigación adecuada.

Al decir de expertos (Juergensmeyer, 2001; RodríguezCarballeira et al., 2009), aunque con matices, el proceso de adoctrinamiento no se utilizaba en las bandas terroristas tradicionales, aunque sí en el mundo de las sectas, conforme lo expone Rodríguez-Carballeira et al. (2015) en su conferencia sobre "El reclutamiento yihadista visto desde las estrategias de captación y adoctrinamiento sectario", donde la integración de sus miembros supone un aprendizaje previo familiar y en sus entornos sociales, anterior a su ingreso en las estructuras terroristas. Esta posición fue variando durante los años de existencia de la banda en función del caudal de jóvenes nacionalistas deseosos de engrosar sus filas para lograr la independencia del País Vasco. Así conviene recordar que, en las décadas de los años sesenta, setenta y ochenta, estos jóvenes se preparaban y esperaban con ansia pertenecer a las filas de ETA. Reinares (2001) presenta esta situación como un auténtico premio, tan atractivo como fichar por un club de fútbol, y Domínguez (1998) como una de las modalidades de captación (casos como los de Juan Carlos Arruti Azpitarte 'Paterra', José Antonio López Ruiz 'Kubati' y Sebastián Echániz Alcorta, entre muchos).

A finales de la década de 1990 se produce un cambio notable, a raíz de la intensa actividad policial y judicial, todo ello unido al creciente desapego social hacia la violencia, expresado por quienes soportaron el terror y se vieron obligados a callar, intelectuales contrarios ideológicamente a tales ideas, políticos que dieron un paso al frente para sustituir a sus compañeros asesinados $y$, en definitiva, toda la sociedad en general, tanto personas como instituciones que rechazaron tales actos violentos, como lo señala Domínguez (2017). Se desmantelaron comandos con mayor rapidez, se perdió el interés masivo de ingreso y la banda pasó a realizar militancia entre aquellos jóvenes idealistas que destacaron con un cierto grado de notoriedad en la comisión de infracciones administrativas denunciadas policialmente o en las protestas convocadas por los grupos afines al MLNV, bajo cualquier pretexto de presión relacionado con circunstancias que sirvieran para convocarlas (detenciones, faIlecimientos de miembros o familiares de presos de ETA o cualesquiera alteraciones sociales contrarias a sus posturas). También se consideró a aquellos detenidos por la comisión de delitos de desórdenes públicos, atentados o amenazas con tipos penales más relevantes, que después fueron seleccionados por el aparato logístico e incluidos en los comandos de la banda terrorista.

En suma, mediante la dinamización de masas a través de los Ilamamientos periódicos de apoyo al mundo de ETA y sus acciones, y con la emergencia de la violencia callejera (kale borroka) como manifestación del mayor 
compromiso de determinados sectores juveniles en favor de la independencia, se presentaron las ocasiones de seleccionar a aquellos jóvenes que, con garantía suficiente de firmeza y convicciones, desempeñarían la lucha a favor de tales posturas. El proceso de captación no resultaba complicado con este caldo de cultivo, pero aun así la organización realizaba ajustes en torno al mismo, para asegurarse la integridad de aquellos miembros que aceptaban incorporarse.

Las organizaciones del MLNV y la propia banda armada se autoproclamaban defensores del pueblo vasco en cuanto a fines, y en virtud de la tan aducida vulneración de derechos buscaban su liberación del sometimiento del Estado español y del francés, que les impedía desarrollarse como nación independiente, presentando una opción bélica de lucha sin tregua para conseguirlo. De ahí que desde sus inicios se proclamara, a modo de revolución en el acta de la $2^{a}$ parte de la $\mathrm{V}$ Asamblea de ETA, celebrada en marzo de 1967 en Guetaria (Guipúzcoa), que:

El nacionalismo revolucionario es, por el contrario, una lucha total, en contra de la opresión nacional y, por tanto, es una lucha revolucionaria [...]. El método de lucha será en espiral ascendente de acción-represión en los cuatro frentes que componen la lucha revolucionaria (cultural, política, económica y militar) para la toma del poder vasco por la clase trabajadora vasca.

La vinculación en sí era un proceso gradual y duradero, con fases de incorporación de la militancia joven e impulsiva a la que se le enseñaban sesgos psicológicos y sociales asimilables a posturas de rechazo del Estado opresor, España, como rasgo de comportamiento nacionalista, a fin de madurar su personalidad antisocial en sintonía con la sociedad paralela de la que habla Elzo (2001), quien la señala como sectarizada en sus ideas y con unos objetivos quiméricos que sirven de sustento a los terroristas. Este proceso se proyectó para que no fuesen advertidos estos comportamientos, por lo menos en el entorno más inmediato, lo que podría obstaculizar la futura integración en la banda armada, tal como se explicaba en el Manual de funcionamiento orgánico de los militantes de ETA, el cual fue encontrado por la Policía Autónoma Vasca, el día 8 de abril de 1998 (Diligencias Previas no 309/98, de 8 de abril), en poder de los miembros del comando Mara, Guillermo Merino Bilbao y Gorka Fraile - a su vez integrantes del complejo Vizcaya-, si bien el texto data del año 1995:
Éramos un grupo de amigos, ahora somos miembros de la organización, tenemos que tener cuidado con la gente. No tenemos que mostrar nada raro. Nos moveremos con total normalidad y ante los de casa y otros compañeros deberemos preparar una explicación, para que no se extrañen demasiado de nuestros movimientos.

Los vinculados realizaban acciones sucesivas de aprendizaje vicario y negativo, también motivadoras de comportamientos violentos. Esto lo explicaba de forma elocuente un integrante de un comando legal desarticulado en la localidad de Barañain (Navarra), al relatar ocho ataques de violencia callejera llevados a cabo con otros integrantes:

Preguntado, si puede enumerar cronológicamente dichas acciones, manifiesta que Sí: Entre noviembre y diciembre del año 2007, en compañía de H. I. participó en el lanzamiento de dos cócteles molotov contra la sede de correos de Barañain. En diciembre del año 2007, antes de finalizar el año y en compañía de H. I., realizó el corte de las contrapesas de las catenarias en dos puntos de la vía férrea: el primero de ellos en Urdiáin y el segundo en Etxarri Aranaz. Que realizaron estas acciones para denunciar las futuras obras del TAV, que quieren hacer pasar por esa zona. (Testimonio de Luis Goñi Lara, integrante del talde Y, comando de kale borroka El Molino, en Barañain (Navarra), según Diligencias $n^{\circ} 230 / 08$, de fecha 23 de agosto, instruidas por la Guardia Civil de Navarra y entregadas en el $\mathrm{JCI}^{\circ}$ 3 de la $A N$ )

En este caso concreto, eran jóvenes iniciados a la temprana edad de 14 o 15 años, con asistencia a concentraciones y al gaztetxe (local juvenil), además de movilizaciones de fin de semana, y que no se integraron como tal en un talde $\mathrm{Y}$ formado por un grupo de amigos hasta los 28 años. En todo caso, sí realizaban acciones menores, para adquirir formación continuada, a modo de peldaños de escalera, como lo explicaba Moghaddam (2005) en su ponencia del curso sobre terrorismo y antiterrorismo, quien aporta con esta teoría/metáfora de la escalera un enfoque sobre la radicalización del militante y su integración en los grupos terroristas.

La etapa adolescente siempre ha sido entendida por los profesionales como un tiempo vulnerable del estado de la personas, y como un tránsito hacia la juventud, donde se forman las opiniones, se ajustan las conductas basadas en la experiencia y se alcanza madurez desde bases educativas y familiares sólidas, resultando esenciales los grupos sociales con los se mezclan y que les sirven de guía futura. Si algo se puede establecer con claridad es 
que aquellos que se insertan en bandas armadas no están locos, ni son psicológicamente diferentes del resto de jóvenes; lo que hasta ahora resulta más evidente, a partir de factores de conocimiento práctico, es que su socialización es muy deficitaria y carente de apoyo educativo y familiar (Rodríguez-Carballeira et al., 2009).

La predisposición del carácter, así como el influjo familiar, tal como refiere Horgan (2005), aportan elementos favorecedores de la personalidad terrorista, que refieren principalmente a experiencias previas en actos de violencia y militancia y a lo que se da en llamar procesos de interacción social, tanto en el contexto comunitario como de implicación con el grupo. Todos los aspectos psicológicos anteriores son reconducibles a la vivencia de experiencias juveniles en alteraciones del orden público o episodios de violencia callejera, que aunque distintas sustancialmente, son preordenadas para poder dedicarse posteriormente y de pleno a la actividad en la que vivirán, en la soledad de una vivienda, ocultos en la clandestinidad, obteniendo información y ejecutando acciones terroristas para a fin de cuentas cumplir largas penas de prisión. Por tanto, una cuestión es la idealización que estas personas tienen y otra muy distinta la vida que les toca vivir si se inclinan por tal opción, explicada en el señalado Manual formativo de funcionamiento orgánico de ETA, donde se detalla cómo se pensó desde los inicios de la organización terrorista el comportamiento de los militantes a partir de su captación, integración y desarrollo de actos de violencia en el seno de la organización armada:

Nuestra vida personal cambiará, pero como los objetivos de nuestra lucha permanecen ahí nuestra militancia continúa. Aunque tengamos que huir de nuestros hogares o ser separados de nuestros amigos seguiremos siendo militantes, manteniendo la disciplina y el ánimo que le corresponde a cada momento y situación nuevos.

\section{Factores de vinculación}

Desde sus inicios en los entornos sociales próximos, era importante generar en los futuros militantes vinculados al grupo terrorista sentimientos de rechazo, odio e incluso venganza hacia quien consideraban el enemigo, atribuyéndole la responsabilidad de las injusticias o privaciones sufridas por su endogrupo, aunque fuesen minoritarias, al punto que en fase práctica no se conoce de adhesiones que hayan sido hechas por injusticias traumáticas, ni tan siquiera por actuaciones violentas con las fuerzas policia- les. Un ejemplo de ello es el caso de Mikel Javier Ayensa Laborda, autor de los asesinatos de un concejal de Pamplona, Tomás Caballero, y de un subteniente del Ejército, Francisco Casanova, e integrante del comando Ekaitza de ETA, desarticulado en Pamplona, Aizoain y Burlada, Navarra (Diligencias Previas 78/2002, de fecha 19 de febrero, instruidas por la Guardia Civil de Navarra y entregadas en el $\mathrm{JCl} \mathrm{n}^{\circ} 1$ de la $\mathrm{AN}$ ), e iniciado en lucha callejera, quien, siendo menor de edad, resultó herido en un ojo en unos disturbios en Pamplona de los que él era participante, al igual que lo hizo en 1994 en otros en Bera (Navarra), durante la celebración del Nafarroa Oinez (celebración de las ikastolas o 'escuelas' de Navarra). Habiendo sido detenido en ambos episodios, el susodicho no reveló ni policial ni judicialmente trastorno previo alguno que le moviera al ejercicio de la violencia, sino que, al contrario, manifestó sentirse estimulado con sus actividades.

Igual patrón se desprende de la investigación llevada a cabo con otros 114 detenidos, quienes fueron captados entre los años 2000 a 2011 como militantes de ETA en Navarra. Ninguno de ellos reveló trauma alguno, y ni siquiera hicieron mención a ello en sus manifestaciones judiciales, aunque sí lo hicieron a posteriori en prisión, plasmándolo en textos escritos a modo de ejemplaridad y realce de sus actuaciones entre sus seguidores y con la dirección ejecutiva de la banda armada, en las denominadas 'autocríticas' o kantadas, comunicaciones orgánicas que todo miembro de ETA tenía que redactar inmediatamente después de su ingreso en prisión, para que el Segurtasun Saila (Departamento o Aparato de Seguridad) de la organización dispusiera de los datos suficientes para tratar de averiguar por qué se había producido la 'caída' (detención/desarticulación), así como los posibles errores cometidos por los miembros del comando, y de esta forma se pudieran adoptar medidas de seguridad y dar directrices a su militancia.

En cuanto al proceso de ideologización o fanatización del subsconciente del militante, se intentó crear un entorno idealista irracional y falso, del que no se es consciente hasta estar en prisión. Esto es una muestra del conocido "efecto gueto" presente en la teoría de cohesión de Festinger (1950), que explica que en tales conductas psicológicas, cualquier elemento discordante de análisis se elimina directamente, porque se tiene la necesidad imperiosa de mantener una postura firme y sin fisuras. Así, los militantes piensan: "No me cuentes historias, dime lo que tengo que hacer", evitando de este modo el estrés, o al menos intentándolo, para no caer en la situación de que "si analizo todas las variables me quedo paralizado". 
De este modo, las decisiones que toman los militantes son mínimamente racionales, guiadas por otros factores, principalmente emocionales y cognitivos. Digamos que los aspirantes a terroristas buscan la heroicidad, y que ese sentido de conducta revela que no son capaces de tener otra. Si el individuo no destaca es porque no tiene esa característica diferencial, canalizadora de sus deseos de forma violenta, que le hace único. No se trata entonces de una preparación educativa superior, ni proveniente en este caso concreto de subterfugios, sino sencillamente de una estrategia conductual hacia determinados comportamientos proyectados para destacar socialmente de cualquier modo, en un ambiente lastrado por la violencia, y fuera de la sociedad democrática. Socialmente, el planteamiento es claro respecto a que en cualquier lugar del mundo el terrorista no pasa de ser un sicario, una escoria, pero en el País Vasco este concepto se estructuró de tal forma que se legitimaba como héroe, en la medida en que "el fin justifica los medios" y todo se permite para conseguir el preciado bien de la independencia, tal como plantean Horgan (2005) y Echeburúa (2001).

De ahí que cuando los militantes son imbuidos de estas ideas durante su integración, nada cambia en sus actuaciones debido al proceso de resocialización o reeducación aplicado, sino que esto se une a las ideas que ya estaban incorporadas, pero procurando no destacar. En ese sentido, Sabucedo (citado en De la Corte et al., 2007) se refiere a que las decisiones que promueven campañas terroristas responden a motivos colectivos ideologizados. Por ejemplo, el etarra Igor Portu Juanena, integrante del comando Elurra de Lesaka (Navarra) que atentó contra la T-4 del aeropuerto de Barajas causando dos muertos, no iba a concentraciones de presos, u otras movilizaciones afines, para no destacar, pero cuando se producían huelgas generales convocadas por el sindicato $L A B$ no acudía a su puesto de trabajo, respetando la conexión citada.

En definitiva, quienes entran a formar parte de un grupo terrorista tienen una socialización previa, al menos ideológica, en su vida diaria, a través de sus organizaciones próximas, en el entendimiento de que sus captadores generan fases sucesivas de aislamiento familiar, de su núcleo de amistades, así como de sus redes de apoyo, colocando al individuo en una situación de mayor vulnerabilidad, aunque ya viniese influenciado por las convencidas ideas nacionalistas de padres y amigos.

La mayoría de los aspirantes cuentan con antecedentes y se encuentran aislados en pequeñas comunidades de amigos, con relaciones endogámicas, por lo que no visibilizan ninguna actividad social o en sus locales de juventud, y cuando son detenidos les fiscalizan incluso hasta en la asignación de sus abogados defensores, en un abuso absoluto de la personalidad de la militancia, registrando y controlando todos los actos de su vida diaria. Así lo expresaba de forma convencida e interiorizada en su manifestación el miembro de ETA Miguel Eguíbar Michelena, en relación con la detención de su hermana:

Preguntado si su hermana ha podido elegir uno $u$ otro abogado dice que sí, que puede elegir uno u otro abogado, eso sí, siempre dentro del Colectivo de Abogados facilitado por Gestoras Pro-Amnistía. Preguntado para que diga si la primera asistencia jurídica de su hermana fue proporcionada por un abogado designado previamente por ella o por la familia Eguíbar, o por el contrario le fue proporcionada asistencia de forma "automática", sin que interviniese para ello una petición previa, manifiesta que sí, que de forma "automática", su hermana se encontró asistida. (Diligencias Previas $n^{\circ} 71 / 1999$, de fecha 10 de marzo de 1999, entregadas en el $\mathrm{JCl} \mathrm{n}^{\circ} 3$ de la $\mathrm{AN}$ )

Con relación a los sectores de apoyo, los promotores de movilizaciones pertenecientes a estructuras del MLNV dirigieron todas sus actividades, homenajes y manifestaciones, sabiendo perfectamente lo que tenían que hacer; incluso algún etarra explicaba, en sintonía con lo expuesto con respecto a la distribución de funciones de captación de otros miembros, que "él no estaba para eso, él estaba para matar" (testimonio de Ibai Ayensa Laborda, integrante del comando Ekaitza en Pamplona, Navarra, autor de dos asesinatos, y proveniente de los grupos de violencia callejera, en las Diligencias Previas $n^{\circ} 81$ y 82/2002, de fecha 28 de febrero de 2002, del JCI número 1 y 2 de la AN, respectivamente), por lo que, de esta forma, nada quedaba a la improvisación.

El entorno también impone la uniformidad de sus miembros y actitudes de comportamiento, lo que miembros de la Gendarmería Nacional Francesa denominan atavismo, con símbolos identificadores, como una determinada estética o indumentaria, y otras características varias. Así, los miembros militantes incorporaban a sus movilizaciones populares simbología propia (banderas de presos e ikurriñas), finalizando los actos con un parlamento en euskera y el anuncio de los siguientes previstos por los convocantes, concluyendo con la entonación del Eusko Gudariak (canto dedicado a los guerreros vascos) y con vivas a ETA. 
Para finalizar la fase del adoctrinamiento psicológico resulta concluyente atribuir todos los males al enemigo, para generar sentimientos de rechazo, odio o incluso venganza hacia ese colectivo, Ilevando a que se deshumanice a las personas que lo componen. Puede servir de ejemplo la pauta etarra de etiquetar como perros a los policías o con apodos de Txotxolo o Mokordo al industrial que iban a asesinar con una bomba lapa, como en el caso del comando Ekaitza desarticulado en Pamplona (testimonio de Francisco Ruiz Romero, miembro de ETA, en las Diligencias Previas $n^{\circ} 78 / 2002$, de fecha 19/02, instruidas por la Guardia Civil de Navarra y entregadas en el JCl $\mathrm{n}^{\circ} 1$ de la AN), de tal forma que a las víctimas se las percibiera como objetos representantes del mal que hay que combatir, entrando en la lógica que hace posible matar sin remordimientos de conciencia, a través del constructo psicológico que Opotow denominó en 1990 como de "exclusión moral" (citado en Martín-Peña, Opotow y Rodríguez-Carballeira, 2011, p. 178).

El proceso de captación de militantes en una organización como ETA exige obviamente de una base de simpatizantes lo más amplia posible, en una comunidad referencial separada de la sociedad democrática, y el desarrollo de una activa propaganda para familiarizar a la población con su movimiento, unido a medios de comunicación favorables a la causa (Egin, Gara, Egunkaria, Euskaldunon, etc.). Así, el perfil ideológico de ingreso se favoreció en el activo círculo amistoso, en la intensidad de los partidos políticos abertzales e independentistas y en la creencia en metas enaltecidas por el activismo de compromiso, sacrificio, disciplina y sobre todo fanatismo que auspiciaba una inserción efectiva, tal como asevera De la Corte (2006).

Los activistas se comportan con violencia y agresividad continua como ingredientes, para realizar sus acciones contra el exogrupo democrático que les estrangula. Esto está en sintonía con el pensamiento propugnado por el antiguo miembro de la banda, Julen Madariaga Aguirre (1964, p. 29): "Si logramos cometer algunos atentados espectaculares, el pueblo quedará como boquiabierto y su reacción general será positiva, tanto más si le hemos ido preparando con nuestra propaganda".

Como se ha dicho, la mayoría de las definiciones de terrorismo, por no decir todas, Ilevan implícito el uso estratégico del terror para alcanzar sus objetivos mediante la planificación y el ejercicio continuo de la violencia sobre la población, causando daños físicos y psíquicos. De la Corte et al. (2007) explican, como primer principio apli- cable al terrorismo con carácter general, que este no debe ser conceptualizado como un síndrome social o psicológico sino como un método de influencia sociopolítica utilizado por minorías para influir en las mayorías por la vía del terror. De este modo, la incertidumbre, la inseguridad y los múltiples costes que conlleva a la población y a los gobiernos afrontar y prevenir esos temas constituyen la simiente con la que los terroristas esperan forzar los cambios a su favor, algo que Kruglanski (2003) dio en Ilamar "influencia social minoritaria" y que indudablemente repercute en los factores de vinculación.

\section{Selección de sus integrantes}

El terrorismo como tal persigue la intimidación colectiva y ese entendimiento se alcanza en nuestro caso, en el sentido que las víctimas directas no suponían para ETA la independencia del País Vasco, pero sí conseguían dos objetivos inmediatos: requerir la atención pública sobre el supuesto problema que padecía el pueblo vasco y a su vez reclamar la negociación del Estado como forma de resolver tan grave cuestión. A esa labor se encomendaba la banda, ejerciendo en términos de Bandura (1990) una "violencia instrumental y llamativa" para conseguir objetivos de carácter político, con un entrenamiento psicológico intenso, según cita Trujillo (2009).

En estricta lógica, el terrorismo solo es posible cuando sus integrantes y colaboradores logran acceder a ciertos recursos imprescindibles, y en este punto cabe recordar que en Francia el grupo terrorista Iparretarrak no avanzó por dos causas esenciales, falta de apoyo social y recursos para la lucha armada, desapareciendo por ello con la detención de su cabeza visible, Philippe Bidart. Esto es algo de lo que España no se apercibió hasta entrada la década de los años noventa, cuando empezó el desmantelamiento del aparato económico y de extorsión de ETA.

Esta banda armada siempre se aseguró la continuación de sus grupos operativos por vía de su propio personal, por familiares o por las organizaciones integrantes del MLNV, impregnados de la idea que debían continuar el camino de los predecesores. Clark (citado por Domínguez, 1998, p. 14) explica que ETA ponía mucho énfasis en la selección de sus miembros:

Después del contacto inicial, si el joven expresa interés en conocer más acerca de la organización, el etarra debe esperar varios meses y contactos para que lo inviten a participar en una simple operación, aunque sea para llevar paquetes o panfletos y hacer pintadas. 
Tal opinión no puede ser compartida en su totalidad, puesto que de la experiencia recogida y visionada se distinguen dos tipos de encuadramientos: primero la militancia de barrio, pueblo o ciudad, donde ya se han puesto de manifiesto las inclinaciones hacia determinados comportamientos que son observados por la organización terrorista y luego, pasado este nivel, cuando se ingresa en la banda. Así lo cuenta el etarra Oscar Calabozo Casado, integrante del comando Vizcaya, quien manifestó ser consumidor de sustancias y contaba con antecedentes penales de dos detenciones por desórdenes públicos y atentado, reuniendo el perfil adecuado que pretende la organización:

Preguntado para que diga cómo se produce su captación para la banda terrorista ETA, manifiesta que le captó Ángel López Anta (miembro de ETA) durante la tregua que se produjo por parte de ETA, que Ángel le dio una nota que el dicente la leyó en casa destruyéndola posteriormente, que en la misma le preguntaban si quería colaborar con la organización terrorista ETA, que dicha nota estaba firmada por "Erakundea". Que el dicente mediante otra nota que le entrega a Ángel López le dice que sí quiere colaborar. El manifestante recibió otra nota de Ángel López diciéndole si quería ser miembro de ETA $(\mathrm{m})$, contestándole el dicente que sí. (Diligencias n $n^{\circ} 37 / 2002$, de fecha 28/03/2002, instruidas por Guardia Civil de Vizcaya y entregadas en el JCI $\mathrm{n}^{\circ} 5$ de la $\mathrm{AN}$ )

Consumada la incorporación se inició la preparación para el ejercicio activo de la militancia en el comando, realizando dos cursillos, sobre explosivos y armas, concretando que el primero de ellos era ya con la premeditada intención de colocar un coche bomba a un militante socialista: "El primer cursillo sobre explosivos lo dieron ya que tenían la intención de colocar un coche bomba a xxxx (político socialista) y no sabían cómo hacerlo". El detenido expuso que toda la instrucción operativa la llevó el dirigente García Gaztelu 'Txapote' en persona y duró tres días, durante los cuales se les explicó el manejo de explosivos y la colocación de bombas lapa, la adopción de medidas de seguridad en los desplazamientos hasta los lugares donde se realizaban los atentados y donde se pernoctaba, e incluso el desarrollo de una fase práctica. Continúa la cita anterior:

Una vez finalizada la teórica, les llevan a una ciudad francesa, donde les enseñan dónde se coloca la bomba lapa en los vehículos; igualmente, estuvieron haciendo práctica con objeto de aprender a calcular bien la distancia cuando se quería atentar contra un vehículo en movimiento. Que las personas que les llevan en la furgoneta y les dan el cursi-
Ilo en el piso, los conocían por los alias de Pello y Txarli. En el segundo cursillo, el cual fue impartido en la misma casa que la vez anterior les fue impartido por Pello y Jokin, que les enseñaron la utilización y manejo de varias armas, como son pistola, metralleta y revólver; que les enseñaron a montarlas, cómo tenían que disparar con ellas; asimismo les enseñaron cómo tenían que hacer las coberturas a la hora de hacer los atentados. Posteriormente les llevaron a un monte, donde estuvieron haciendo prácticas de tiro con las armas descritas anteriormente.

En el caso del también miembro de ETA Francisco José Ramada Estévez, encargado de realizar secuestros de la banda terrorista en aquel momento, parece pertinente comenzar por señalar que nació en la localidad de Bera (Navarra), en el seno de una familia de tres hermanos de procedencia gallega, y que desde pequeño era conflictivo y conocido por los guardias civiles del puesto de su residencia, quienes apuntaban a que se convertiría en un delincuente habitual. Era impulsivo y no dejaba de cometer las típicas fechorías que lo incardinaban como tal, pero en absoluto relacionado con el nacionalismo abertzale. De hecho, cuando alcanzó la mayoría de edad fue detenido por sustraer un turismo en Guipúzcoa y desde allí se encaminó a residir en la población de Etxarri-Aranaz (Navarra), donde completó su formación educativa y se insertó en la banda terrorista junto a su pareja, Sagrario Yoldi Múgica. Cuando fue detenido explicó su captación (Diligencias 702/2001, de fechas 08/01/2001, instruidas por Policía Nacional y entregadas en el JCI no 3 de la AN), manifestando que entre los años 1993 y 1994 recibió una carta en su domicilio que le proponía iniciar su militancia a través de una cita en Burdeos (Francia), en un lugar predeterminado al que debía acudir con una contraseña, consistente en un periódico Marca y un paquete de cigarrillos marca Camel en la mano. En este caso, el responsable de la captación era José Javier Arizcuren 'Kantauri', quien en el mismo momento del encuentro le propuso la actividad a desarrollar, pese a no conocerse de nada:

Preguntado para que explique lo más detalladamente posible cuál era su actividad en dicha organización terrorista, manifiesta: que Kantauri le propone si quiere participar en la elaboración de secuestros a lo que manifiesta su consentimiento. Que en ese momento Kantauri le dice que empiece a buscar un local que reúna determinadas características de seguridad para construir una cárcel del pueblo y que le busque una cobertura legal como pudiera ser la creación de una empresa. Que su actividad dentro de la citada organización terrorista era la de realizar secuestros de empresarios con el fin de recaudar dinero para la citada banda armada. 
No pasó ningún periodo de tiempo, sino que directamente Kantauri le ofreció su función en atención a su valía, pues conocía la zona donde colocar los zulos (locales) para situar a los secuestrados, además de que se mostraba decidido y convencía por su proceder social anterior, lo cual no es un caso aislado en la militancia, como se deduce de la continuación de la cita anterior:

Preguntado para que explique cuántas personas han sido secuestradas y ocultadas en el citado "zulo", manifiesta: Que dos, que eran José María Aldaya y Cosme Delclaux. Que estos dos secuestros los realiza el declarante con los liberados "Santi" y "Tere", consistiendo su actuación en que una vez que los miembros liberados hubiesen realizado el secuestro, mantener una cita con ellos en un lugar preestablecido y realizar el cambio de vehículo y traslado del secuestrado al inmueble referido. Que para la realización de dichos actos utilizaba su propio vehículo un Volkswagen Golf.

Del relato de adhesión de Ramada Estévez, así como de otros muchos, se deduce que para la captación, en virtud de las facultades e historial previo que presentaban, se integra a los militantes en los distintos aparatos de información, logística o en los comandos armados ofensivos, si presentan comportamientos aguerridos y se muestran capaces de cometer acciones contra la vida de las personas o contra los bienes de forma inmediata.

\section{Proceso de reclutamiento de la banda terrorista ETA}

El ingreso en la organización se daba en función de sus necesidades, no como la fase final de un largo proceso en que el aspirante va haciendo méritos y demostrando su capacidad, sino todo lo contrario, asociado a sucesivos periodos según las necesidades operativas. Lo habitual era que, en un plazo muy breve de tiempo, a veces pocos días, una persona pasara de no tener ninguna vinculación orgánica a estar integrada y provista de material para perpetrar atentados, pero siempre en función de sus características personales y de la escasez de militantes decididos a arriesgar sus vidas en la consecución de sus fines.

Lo primero que destacaba en este proceso de ETA era su estructura para la captación de miembros comprometidos, que no era masiva, sino estricta y con una labor concienzuda de conocimiento a través de terceros en la organización política, que iban proporcionando la información necesaria respecto de aquellos que se mostrasen idóneos y opacos en su conducta diaria, aunque en los últimos años la situación cambió radicalmente, echando mano de todos aquellos que presentaban antecedentes penales y administrativos.

El proceso de reclutamiento de miembros de ETA se puede clasificar en cinco modelos de captación, según explica Domínguez (1998): a) aquellas actividades lideradas por los miembros de un comando para completar sus grupos o ampliar sus acciones; b) las realizadas por activistas liberados; c) las comandadas por la dirección de ETA, en atención a las informaciones recibidas por el aporte de sus distintos canales; d) las captaciones realizadas a partir de las informaciones aportadas por otros miembros del aparato de apoyo; y e) las de los colaboradores que se ofrecían de propia iniciativa, deseosos de integrarse.

En el primer caso, el captador era el jefe del comando, quien mantenía los contactos regulares con la dirección ejecutiva, para asegurarse un grupo organizado y necesitado únicamente de armas y explosivos. Este procedimiento, característico de los primeros años, entraría en decadencia con el tiempo, aunque se volvió a recuperar a finales de la década de los noventa, como en el caso del comando Ekaitza en Navarra, en el cual el jefe del mismo, Patxi Ruiz Romero, reclutó a los restantes componentes, a excepción de Ibai Ayensa, quien fue incorporado por su propio hermano, Mikel. No obstante, la regularidad absoluta no es característica de las formas de actuación en la cronología de la banda, que cuando le convenía cambiaba de estrategia para favorecer a la organización. Con respecto a la captación por parte de los liberados, se refiere a la que conseguía la integración en la organización de un nuevo militante a través del activismo territorial, método también anticuado, pero estable en el tiempo y en zonas donde imperaba un cierto liderazgo ejercido por destacados miembros de ETA que eran oriundos del lugar (es el caso de López Ruiz 'Kubati', García Gaztelu 'Txapote' o Jorge Olaiz en Navarra).

La adhesión a los fines de ETA se visibilizó especialmente por la vía de las visitas a miembros huidos al sur de Francia, proceso que se realizó durante años por parte de amigos y familiares, lo que supuso el aporte de los Ilamados refugiados políticos, militantes idealizados en la dedicación íntegra a la lucha por la independencia del País Vasco. Las cuadrillas de captación se desplazaban para pasar tiempo con ellos, y los miembros de los comités de apoyo llevaban ropa u otros efectos al otro lado de la frontera, en la medida en que aquellos se habían visto obligados a pasar de la clandestinidad a otros sitios alejados al norte 
de Francia, o a otros países con comunidad de intereses revolucionarios, incluso en Hispanoamérica, dada la presión policial, según lo expresa Ramírez (1984):

Estas cuadrillas se han convertido, sobre todo en la época de los años 70, en auténticos dinamizadores étnicos. Por sí mismas y por medio de las asociaciones colectivas de las que pudieran formar parte, por medio de las actividades de estas (manipulación de símbolos —-bandera, himno, etc.-, cultivo y promoción del euskera, organización de fiestas, actividades culturales y deportivas, marchas, etc.), las cuadrillas han colaborado de una manera fundamental al refuerzo de la conciencia vasca. (p. 218)

El tercer grupo minoritario estuvo representado por aqueIlos que se ofrecían directamente para entrar en ETA, gestionando los contactos necesarios para entrevistarse con los responsables de la organización, a los que expresaban su propósito de ingresar en el grupo. Estas personas se destacaban por su juventud y agresividad, aunque sobre todo por su disposición plena para integrarse, puesto que no trabajaban ni estudiaban, solo se preparaban para ser miembros, con una edad media de poco más de 22 años. Este método desapareció luego en la dirección ejecutiva de la banda, prácticamente por la falta de confianza en el procedimiento, pues se sospechaba de la posible infiltración de miembros de las Fuerzas y Cuerpos de Seguridad del Estado (FCSE). Así lo relató Agustín Almaraz Larrañaga, miembro del comando Sierra Madre o Fidel Castro de ETA (integrado en el complejo Araba 1995), en el curso del Atestado AA/0011/95 de la Policía Autónoma Vasca:

Preguntado sobre cómo y cuándo se produce su captación para participar en las actividades de la organización terrorista ETA, manifiesta que junto con José Ignacio ALONSO al que conoció en la Escuela Náutica de Pasajes, Gipuzkoa, estudiando, como tenían conocimiento de la militancia de Jorge GONZÁLEZ ENDEMAÑO en K.A.S. Nacional, deciden hablar con éste y ofrecerse para prestar colaboración con la organización ETA, solicitando a Jorge que a través de sus contactos les ponga en contacto con la organización. (Diligencias Previas n ${ }^{\circ} 456 / 95$. JCl n ${ }^{\circ} 4$ de la AN)

El cuarto método de reclutamiento consistía en el envío de cartas a militantes seleccionados, situación que exigía una estructura centralizada de abordaje diferente de los anteriores, ya que los dirigentes o delegados debían intervenir en los envíos, concertando citas y reuniones con el seleccionado para tratar de persuadirle. Este procedimiento originaba disfunciones, tal como sucedió con los integrantes del comando Nafarroa, Santiago Díez Uriarte y Javier Goldáraz Aldaya, desarticulado en Pamplona en el año 1992, quienes fueron denunciados en los juzgados tras intentar captar a miembros por carta para colaborar con el citado grupo, algo que los radicales entendieron como una estrategia policial que publicaron incluso en el diario Egin (Domínguez, 2006).

Las relaciones existentes entre aquellos que integraban el aparato logístico siempre procuraron seguir unos determinados parámetros, esencialmente de seguridad, por lo que se pueden agrupar en tres tipos generales: (i) circunscritos a familiares, (ii) derivados de amistad, y (iii) por activismo político, cultural o social, principalmente. La presencia de vínculos de amistad revela que la reproducción de la banda armada se daba en un ambiente marcado por los lazos personales, de confianza y cercanía entre los protagonistas, como se afirma en el siguiente pasaje:

Pero no solo queremos destacar las cuadrillas como mecanismos de integración comunitaria, sino como mecanismos de recepción, recreación y reformulación de contenidos de diferenciación cultural en el marco de un proceso de revitalización étnica, sobre todo gracias a su posición estratégica intersticial en la vida cotidiana de la comunidad. Estas redes, este entramado de la sociedad civil, se han convertido, sobre todo en un momento histórico muy concreto, en lugares privilegiados de recepción y amplificación de un código simbólico étnico "nosotros-ellos", delimitando y definiendo claramente espacios y criterios de pertenencia diferenciada. Estas cuadrillas se han convertido, sobre todo en la época de los años 70, en auténticos dinamizadores étnicos. (Ramírez, 1984, p. 218)

Confirma esta idea Domínguez (2006), quien califica a la cuadrilla como "un grupo social informal, pero de lazos contundentes, que tiene capacidad para subvertir los valores familiares y cambiarlos por otros radicalmente contrarios". Tras las relaciones de amistad, son las familiares las que predominan en los procesos de captación de ETA (novios, cónyuges, padres-hijos). Conviene citar casos como el de Lourdes Churruca, cuyo marido, Félix Irazabalbeitia, murió en un enfrentamiento con la Ertzaintza (policía autonómica del País Vasco), el de José Luis Barrios Martín, captado por la madre de su novia, o el de Nerea Garro y sus dos hermanos gemelos, entre otros. Esto permite deducir que la relación familiar tenía un importante peso específico para garantizar la fidelidad grupal.

También se puede considerar la existencia de relaciones derivadas de un nexo de militancia política o sindical común, participativo en actividades culturales, en el ri- 
tual colectivo y cotidiano del poteo (recorrido por bares tomando vinos) y, sobre todo, en los lugares habituales de concienciación y crítica nacionalista, de apoyo a la violencia de ETA y de rechazo colectivo al Estado. Destacaba con esto la presencia activa del entorno social de militantes en gaztetxes, herriko tabernas (locales y bares) y zonas urbanas, así como en actos de violencia callejera, en los cuales ya no había motivo para guardar silencio sino que la exposición pública del rechazo estatal debía ser visible para congratularse con el grupo, como lo relata Nerea Bengoa Ciarsolo, laguntzaile del comando Sierra Madre o Fidel Castro (complejo Araba 1995), en el Atestado AA/0011/95 de la Ertzaintza: "Preguntada sobre su actividad laboral, manifiesta que trabaja de vez en cuando de tabernera en la Herriko Taberna del Casco Viejo de Vitoria, no percibiendo sueldo alguno" (Diligencias Previas $\mathrm{n}^{\circ} 456 / 95$ entregadas al $\mathrm{JCl} \mathrm{n}^{\circ} 4$ de la AN).

Los datos expuestos evidencian que la renovación mayoritaria de la plantilla de ETA se produjo en un contexto ideológico concreto, como serían algunos partidos políticos o sindicatos, así como en el ámbito de las relaciones personales, dejando de apreciarse la existencia de unos focos institucionales externos, como los grupos de montaña, o culturales, que en otros momentos de la historia de ETA tuvieron importancia. En su etapa final, casi un $40 \%$ de los activistas estaban integrados en algún partido, sindicato u organización política, o bien realizaban algún tipo de actividad de apoyo. La mayor proporción formaba parte de alguna organización de KAS (HASI, LAB, JARRAI, etc.) o militaba en otros organismos dependientes de estas (GG. AA., Ikasle Abertzaleak) o en el partido político Herri Batasuna. Al final todos se insertaban e incluso trabajaban en organizaciones nacionalistas, pero la mayoría procedían de círculos de amistad, como lo fue siempre históricamente.

\section{Conclusiones}

Conocido el devenir histórico de ETA y los procesos de debate con directrices específicas impartidas a la militancia por su comité ejecutivo, resulta necesario explorar dicho proceso de integración y transmisión en futuras investigaciones, para completar la comprensión del reclutamiento terrorista.

Como se ha expresado, de las diligencias instruidas por fuerzas policiales, así como de manifestaciones de detenidos insertas en el curso de los sumarios judiciales de la Audiencia Nacional, se fueron conociendo progresi- vamente las distintas formas históricas de actuación de la dirección de la banda y sus aparatos, al igual que su composición estructural, las instrucciones dictadas, la operación de los comandos, todo lo cual, completado con el conocimiento directo e inmediato de actuaciones con todo el entorno social y militante, supone un mayor aporte al estudio del terrorismo, para apoyar los conocimientos teóricos y las posiciones conductuales de expertos.

A partir de esto se puede establecer que la captación era un proceso en cadena, dentro del entorno más radical y proclive a ese proselitismo, consiguiendo así la casi total aceptación del compromiso y, por otro lado, preservar la seguridad de los activistas al moverse en un entorno de difícil penetración para las Fuerzas y Cuerpos de Seguridad.

En suma, se comparte el criterio de Hoffman (2019), quien expone con claridad meridiana que en los procesos de radicalización y reclutamiento en bandas terroristas quedan descartadas las hipótesis de la existencia de una condición social o personalidad dispuesta que impulse la condición de terrorista, sin condiciones externas que la favorezcan, ni comportamientos o entornos sociales individualizados, ni planteamientos generalistas de reclutamiento. Se estima que no existe un único camino hacia la inserción en las bandas armadas, y que los motivos son poderosamente personales, pero basados posiblemente en una de los siguientes factores: frustración, agravio, deshonra, religión, cambio sociopolítico fundado en el nacionalismo o separatismo, o por compromiso hacia la revolución.

En nuestro caso, los terroristas en sí estuvieron motivados por un profundo sentido del altruismo equivocado y la convicción subyacente de la violencia legítima, así como por el compromiso moralista y de autosacrificio que logró atraer militancia hacia el grupo de forma colectiva para luchar por la independencia del País Vasco. Por otra parte, las limitaciones en las investigaciones residen en el lento aporte de documentación existente en Francia sobre la banda terrorista, la complejidad de su interpretación y de confrontación de indicios por el inexorable paso del tiempo, así como por la circunspección social de la sociedad vasca y navarra en las entrevistas realizadas, que no favorece el necesario conocimiento.

Una década después del cese definitivo de la organización terrorista ETA, y como síntesis del estudio y análisis sobre su modus operandi a lo largo de los años, se puede señalar cómo la banda fue adaptando y evolucionando en sus macabros métodos para sembrar terror. Muchos 
de estos procesos fueron sistemáticos y dejaban poco margen a la innovación y el cambio, como era el caso de la captación, donde nos movemos en el terreno de lo social y lo psicológico, en la propia idiosincrasia de los jóvenes radicales, fiel reflejo de ese proceso evolutivo, desde la épica revolucionaria de entonces a la actual movilización social y de masas (manifestaciones, dinámicas, etc.) y, en el peor de los casos, a la comisión de acciones violentas. Con todo, se concluye que se debe continuar con las investigaciones de carácter específico, capaces de esclarecer las particulares causas de todos los atentados pendientes, como se vienen resolviendo en los últimos tiempos, amparados en el conocimiento preciso de los antecedentes del reclutamiento, las conexiones con los distintos comandos y la verificación de pruebas existentes de forma detallada.

\section{Referencias}

Bandura, A. (1990). Mechanisms of moral disengagement. En W. Reich (Ed.), Origins of Terrorism: Psychologies, Ideologies, Theologies, States of Mind (pp. 161-191). Cambridge University Press.

De la Corte, L. (2006). La lógica del terrorismo. Alianza Editorial.

De la Corte, L. (2007). Algunas claves psicosociales para el análisis y la aplicación de los fenómenos terroristas. Athena Paper, 2 (3), artículo 3/4.

De la Corte, L., Kruglanski, A., De Miguel, J., Sabucedo, J. M. y Díaz, D. (2007). Siete principios psicosociales para explicar el terrorismo. Psicothema, 19 (3), 366-374.

Domínguez, F. (1998). ETA: Estrategia organizativa y Actuaciones 1978-1992. Servicio Editorial Universidad País Vasco.

Domínguez, F. (2004). ETA: Un análisis de situación. Cuadernos de pensamiento político, (4), 93-116.

Domínguez, F. (2006). Dentro de ETA. La vida diaria de los terroristas. Punto de Lectura S. L.

Domínguez, F. (2017). Las claves de la derrota de ETA. Informe del Centro Memorial de Víctimas del Terrorismo $n^{\circ}$ 3. Editorial MIC.

Echeburúa, E. (octubre 17, 2001). Por qué y cómo se llega a ser terrorista. Diario $A B C$.
Elzo, F. J. (2001). Reto 1: Sociedad Civil. La dimensión socio-cultural. Universidad de Deusto.

Festinger, L. (1950). Informal social communication. Psychological Review, 57, 271-282.

Garrido, V. y Gómez, A. M. (1998). Diccionario de Criminología. Editorial Tirant lo Blanc.

Hoffman, B. (2019). Conferencia sobre "Reclutamiento y Radicalización: Perfiles terroristas". Curso Terrorismo y Antiterrorismo de la Universidad de Georgetown.

Horgan, J. (2005). Psicología del Terrorismo. Cómo y por qué alguien se convierte en terrorista. Editorial Gedisa.

Juergensmeyer, M. (2001). Terror in the Mind of God. University of California Press.

López, R. (2014). Informe Foronda. Los contextos históricos del terrorismo en el País Vasco y la consideración social de las víctimas. 1968-2010. Instituto de Historia social "Valentín de Foronda". Universidad del País Vasco.

Kruglanski, A.W. (2003). Terrorism as a tactic of minority influence. Ponencia presentada en el congreso sobre Active minorities: hoping and coping, Grenoble.

Madariaga, J. (1964). La insurrección en Euskadi. Cuadernos de ETA, (20).

Martín-Peña, J. Opotow, S. y Rodríguez-Carballeira, Á. (2011). Amenazados y víctimas del entramado de ETA en Euskadi: un estudio desde la teoría de la exclusión moral. Revista de Psicología Social, 26 (2), 177-190.

Moghaddam, F. M. (2005). La escalera al terrorismo: una exploración psicológica. American Psychologist, 60 (2), 161-169.

Opotow, S. (1990). Moral exclusion and injustice: An overview. Journal of Social Issues, 46, 1-20.

Ramírez, E. (1984). Cuadrillas en el País Vasco, identidad local y revitalización étnica. Reis, 25, 213-220.

Reinares, F. (2001) Patriotas de la muerte - Quiénes han militado en ETA y por qué. Editorial Taurus.

Rodríguez-Carballeira, Á., Martín-Peña, J., Almendros, C., Escartín, J., Porrúa, C. y Bertacco, M. (2009). Un análisis psicosocial del grupo terrorismo como secta. Revista de Psicología Social, 24 (2), 183-195. 
Rodríguez-Carballeira, Á., Echeverría, C., Lozano M., Rabe, Mohamed., Gómez, J., Benítez, R., Llamas, M., Gómez, M. y Miró, F. (2015). Simposio sobre la amenaza presente y futura del terrorismo yihadista. Claves para la prevención. Cuadernos de política criminal, 115 (Época II), 405-430.

Sanmartín, J. (2005). El terrorista. Cómo es. Cómo se hace. Editorial Ariel S. A.
Trujillo, H. M. (2009). Hacia una mejor comprensión psicológica del terrorismo: reclutamiento ideología y violencia. Revista de Psicología Social, 24 (2), 163-181.

Turvey, B. (1999). Criminal Profiling. Academic Press. 